\title{
Classification, Structure, and Bioactive Functions of Oligosaccharides in Milk
}

\author{
Mohammad Al Mijan, Yun-Kyung Lee, and Hae-Soo Kwak* \\ Department of Food Science and Technology, Sejong University, Seoul 143-747, Korea
}

\begin{abstract}
Milk oligosaccharides are the complex mixture of six monosaccharides namely, D-glucose, D-galactose, $N$-acetyl-glucosamine, $\mathrm{N}$-acetyl-galactosamine, L-fucose, and $\mathrm{N}$-acetyl-neuraminic acid. The mixture is categorized as neutral and acidic classes. Previously, 25 oligosaccharides in bovine milk and 115 oligosaccharides in human milk have been characterized. Because human intestine lacks the enzyme to hydrolyze the oligosaccharide structures, these substances can reach the colon without degradation and are known to have many health beneficial functions. It has been shown that this fraction of carbohydrate can increase the bifidobacterial population in the intestine and colon, resulting in a significant reduction of pathogenic bacteria. The role of milk oligosaccharides as a barrier against pathogens binding to the cell surface has recently been demonstrated. Milk oligosaccharides have the potential to produce immuno-modulation effects. It is also well known that oligosaccharides in milk have a significant influence on intestinal mineral absorption and in the formation of the brain and central nervous system. Due to its structural resemblance, bovine milk is considered to be the most potential source of oligosaccharides to produce the same effect of oligosaccharides present in human milk. This review describes the characteristics and potential health benefits of milk oligosaccharides as well as the prospects of oligosaccharides in bovine milk for use in functional foods.
\end{abstract}

Key words: oligosaccharide, bovine milk, bioactive function, classification

\section{Introduction}

Oligosaccharides are one of the substantial bioactive milk components. These substances have been considered as the drawback among the many beneficial functions of milk until multifarious bioactive roles of milk oligosaccharides have been realized. The first ever identified functional role of milk oligosaccharides is denoted as prebiotic effect (Coppa et al., 2006). Milk oligosaccharides perform as a soluble receptor for many pathogenic bacteria and in addition lower the $\mathrm{pH}$ in the gut. The acidic ambience in the gut has threefold function: 1) it favors the growth of beneficial bacteria, 2) it destroys harmful microorganisms, and 3) it avails the mineral absorption. Additionally, in the brain development and memory formation during infanthood, sialylated milk oligosaccharides act as one of the key factors (Boehm and Stahl, 2007).

The growing interests are focused upon the structural

*Corresponding author: Hae-Soo Kwak, Department of Food Science and Technology, Sejong University, Seoul 143-747, Korea. Tel: 82-2-3408-3226, Fax: 82-2-3408-4319, E-mail: kwakhs@sejong.ac.kr aspects of milk oligosaccharides as the bioactive functions of milk oligosaccharides are revealed. Accordingly, 25 oligosaccharides in bovine milk and 115 oligosaccharides in human milk have been completely characterized till today. Generally, bovine milk oligosaccharides (BMO) are structurally different from human milk oligosaccharides (HMO), nonetheless, many of the BMO are found to be very similar to HMO. In particular, both bovine and human milks are abounded with sialylated oligosaccharides, especially at the early lactation period. The concentrations of oligosaccharides in mature human milk and colostrum are 12-13 g/L and 22-24 g/L, respectively, whereas, bovine milk contains $30-60 \mathrm{mg} / \mathrm{L}$ oligosaccharides but the amount can goes up to $1 \mathrm{~g} / \mathrm{L}$ in case of cow colostrums. Moreover, structural diversity and complexity of HMO is very high. While complexity in structure of HMO restrains its feasibility to be used in functional foods, BMO showed rather simpler structure (Gopal and Gill, 2000; Martinez-Ferez et al., 2006; Mehra and Kelly, 2006; Urashima and Taufik, 2010).

Due to the presence of $\alpha$ - and $\beta$-linkages, milk oligosaccharides reach the intestine intact and eventually are utilized by the health promoting bifidobacteria. The 
breakdown of milk oligosaccharides gives rise to shortchain fatty acids which inhibits the growth of harmful bacteria by bringing down the $\mathrm{pH}$ (Barile et al., 2009). Milk oligosaccharides have a unique structure to act as a soluble ligand against infective bacteria to protect the gastrointestinal, respiratory, and urinary tracts. It is recently discovered that a trace amount of milk oligosaccharides are absorbed through the gut and interact directly with the immune system to modulate the immune response (Kunz and Rudloff, 2006).

The sialylated milk oligosaccharides exhibit a special function in brain development. This fraction of milk oligosaccharide takes part in the synthesis of ganglioside and glycoprotein which comprise a large part of the brain cortex (Bogoch, 1977; Schmidt, 1989; Wang and BrandMiller, 2003). It has been perceived that sialylated oligosaccharides are also very important in the functions of central nervous system (Schauer and Kamerling, 1997; von Itzstein and Thomson, 1997). Acidic oligosaccharides in milk have been found effective against inflammatory diseases (Boehm and Stahl, 2003). Milk oligosaccharides are reported to play an essential role to stimulate the absorption and transport of some minerals in the gastrointestinal tract through direct and indirect mechanisms (Mills et al., 2011).

It is supported by literature that oligosaccharides in bovine milk are analogous to $\mathrm{HMO}$, implying similar physiological functions (Gopal and Gill, 2000; Urashima et al., 2001). Concentrations of oligosaccharides in bovine milk are very low but recently it is discovered that whey permeate can be a novel source of complex oligosaccharides with the strcuctural resemblance and diversity of oligosaccharides in human milk (Barile et al., 2009; Urashima et al., 2001). Therefore, this review will discuss on the structural aspects of oligosaccharides in milk and more importantly the bioactive functions of milk oligosaccharides with a special emphasis on oligosaccharides in bovine milk.

\section{Classification and structures of oligosaccharides}

According to the latest definition of oligosaccharide by IUPAC-IUBMB Joint Commission of Biochemical Nomenclature, the borderline between oligo- and polysaccharides cannot be drawn rigorously; instead, the term oligosaccharide is commonly used to refer to defined structures as opposed to a polymer of unspecified length (IUPAC/ IUBMB, 1997). However, some authorities defined oligosaccharides as carbohydrates with a maximum polymer of monosaccharides up to 10 (Gopal and Gill, 2000) and as there is no physiological or chemical reason to set the limit of polymers, other authorities defined oligosaccharides as ranging from a degree of polymerization of 3 up to 19 (Mussatto and Manchillha, 2007).

It used to be believed that oligosaccharides are the accompanied consequences of high concentration of lactose in milk and they are produced neither by specific synthesis nor by degradation of glycolipids (Kobata et al., 1970; Urashima et al., 2001). In fact, interest in milk oligosaccharides started nearly about a hundred years back when it was observed that this component of milk potentially plays a role in the development of bifidogenic bacteria in breastfed infants (Kunz et al., 2000; MartinezFerez et al., 2006). Milk oligosaccharides are hydrolyzed as monosaccharides (D-glucose, D-galactose, N-acetylglucosamine, N-acetyl-galactosamine, L-fucose, and Nacetyl-neuraminic acid). These components combine in different ways to form a large number of oligosaccharides (Fig. 1) (Kunz et al., 2000; Sabharwal et al., 1991). However, milk oligosaccharides categorized broadly into acidic and neutral types (Gopal and Gill, 2000; Kunz and Rudloff, 2006). Neutral oligosaccharides do not contain any charged monohydrate residues while acidic oligosaccharides contain one or more residues of $\mathrm{N}$-acetylneuraminic acid (sialic acid) which are negatively charged. About 200 different human milk oligosaccharides (HMO) have been identified and studied by high performance liquid chromatography (HPLC)-mass spectrometry (MS) until now, among which at least 115 oligosaccharides have been completely characterized (Ninonuevo et al., 2006; Urashima and Taufik, 2010). Tao et al. (2008), and Urashima and Taufik (2010) stated that 25 bovine milk oligosaccharide structures have been determined out of 39 detected oligosaccharides.

The concentration of oligosaccharides in the milk of most mammalian animals is much lower compared to human milk (Urashima et al., 1997b). In contrast to human milk oligosaccharides (HMO), fucosylated oligosaccharides are very rare in the neutral fraction of oligosaccharides of animal milk. On the other hand, sialic acid is the most important structural element of the acidic fraction of the animal milk oligosaccharides (Boehm and Moro, 2008). Ten sialyl oligosaccharides were found in bovine colostrum which contained both Neu5Ac and Neu5Gc, whereas human milk or its colostrum showed only Neu5Ac (Urashima et al., 2001). While 3'- and 6'-sialyllactose, and 3'and 6'-galactosyllactose are common to human and bovine milks, the structures of other sialyl oligosaccharides are different from the two types of milk (Boehm and Stahl, 


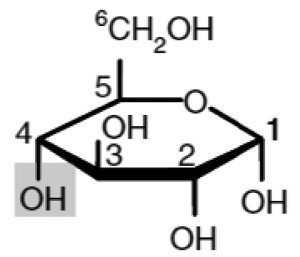

Glucose

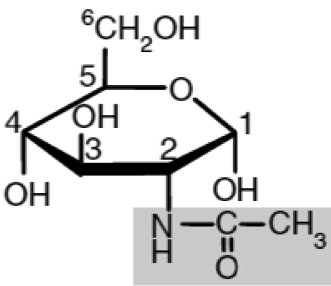

N-Acetyl-glucosamine

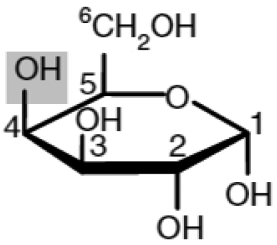

Galactose

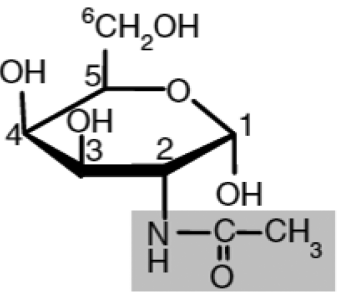

N-Acetyl-galactosamine

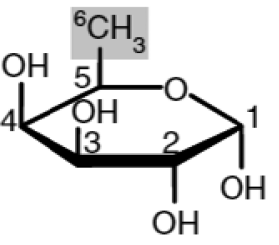

Fucose

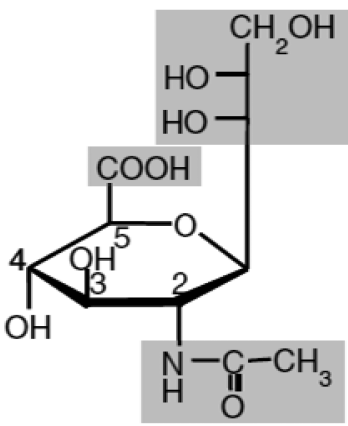

N-Acetyl-neuraminic acid $=$ sialic acid

Fig. 1. Monosaccharide units of oligosaccharides in bovine and human milk (Kunz et al., 2006).

2003). In bovine milk, the concentration of oligosaccharides falls down during lactation except in late lactation, when the level of sialylated oligosaccharides increases (Martin et al., 2001). Fructooligosaccharides (FOS) and galactooligosaccharides (GOS) which are considered as functional oligosaccharides are structurally different from HMO and BMO since the FOS and GOS are linear structures containing repeating units of galactose and fructose while HMO and BMO are branched structures and display a variety of $\alpha$ - and $\beta$-linkages (Fig. 2) (Barile et al., 2010; Tao et al., 2008; Zivkovic and Barile, 2011).

Interestingly, compared to other animal milks, goat milk has been shown to have a very high amount of oligosaccharides. According to a study by Martinez-Ferez et al. (2006), the oligosaccharide content in goat milk was measured in the range of 250 to $300 \mathrm{mg} / \mathrm{L}$ which is 4 to 5 times higher than the amount of oligosaccharides found in bovine milk. But caprine milk shows fewer numbers of oligosaccharides than bovine milk (Table 1). Besides, bovine milk is considered as superior to caprine milk as well as to any other animal milk in terms of structural closeness of its oligosaccharides to HMO; furthermore, the bulkiness of bovine milk and its wide acceptability to consumers make it the most suitable to be used in the functional foods.
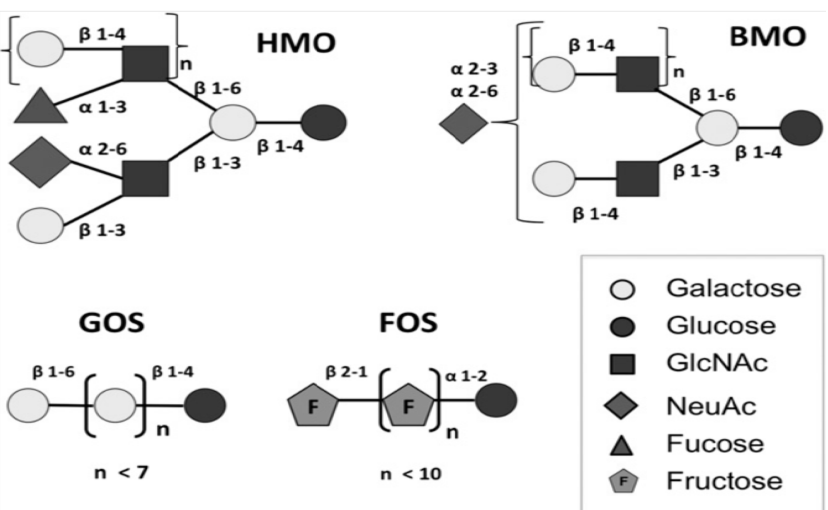

Fig. 2. Schematic oligosaccharide structures from human milk, bovine milk, galactose and fructose (Zivkovic and Barile, 2011). Linkages are shown as $\alpha 1-2, \alpha 1-3$, $\alpha 2-3, \alpha 2-6, \beta 1-3, \beta 1-4, \beta 1-6$, and $\beta 2-1$.

\section{Bioactive functions of oligosaccharides in milk}

It has been thought for many years that the milk oligosaccharides had the function only in the development of the specific intestinal bifidogenic bacteria in breast-fed infants (Rivero-Urgell and Santamaria-Orleans, 2001). In addition to the prebiotic activity, recently, it is well known that oligosaccharides act as a soluble receptor for many pathogenic microorganisms and thus play an important role to protect infections (Barile et al., 2009; Boehm and Stahl, 2007; Gopal and Gill, 2000). According to a study 
Table 1. Oligosaccharides in bovine and caprine milk or colostrum

\begin{tabular}{|c|c|c|c|}
\hline Structure & Name & Source* & Reference \\
\hline \multicolumn{4}{|l|}{ Neutral oligosaccharides } \\
\hline $\operatorname{GalNac}(\beta 1-4) \mathrm{Glc}$ & $\mathrm{N}$-acetylgalactosaminylglucose & $\mathrm{b}$ & Saito et al., 1984 \\
\hline Gal $(\beta 1-4)$ GlcNAc & $N$-acetyllactosamine & $\mathrm{b}$ & Saito et al., 1984 \\
\hline $\operatorname{Gal}(\beta 1-4) \mathrm{Fuc}(\alpha 1-3) \mathrm{GlcNAc}$ & 3-fucosyllactosamine & $\mathrm{b}$ & Saito et al., 1987 \\
\hline $\operatorname{GalNAc}(\alpha 1-3) \operatorname{Gal}(\beta 1-4)$ & $\alpha 3^{\prime}-N$-acetylgalactosaminyl-lactose & $\mathrm{b}$ & Urashima et al., 1991b \\
\hline $\operatorname{Gal}(\alpha 1-3) \mathrm{Gal}(\beta 1-4) \mathrm{Glc}$ & $\alpha 3^{\prime}$-galactosyllactose & $\mathrm{b}, \mathrm{c}$ & $\begin{array}{l}\text { Urashima et al., 1991b; Urashima et al., } \\
1994\end{array}$ \\
\hline $\operatorname{Gal}(\beta 1-3) \mathrm{Gal}(\beta 1-4) \mathrm{Glc}$ & $\beta 3$ '-galactosyllactose & $\mathrm{b}, \mathrm{c}$ & Saito et al., 1987; Urashima et al., 1994 \\
\hline $\operatorname{Gal}(\beta 1-4) \mathrm{Gal}(\beta 1-4) \mathrm{Glc}$ & $\beta 4$ '-galactosyllactose & $\mathrm{c}$ & Kimura et al., 1997 \\
\hline $\operatorname{Gal}(\beta 1-6) \mathrm{Gal}(\beta 1-4) \mathrm{Glc}$ & $\beta 6$ '-galactosyllactose & $\mathrm{b}, \mathrm{c}$ & Saito et al., 1987; Urashima et al., 1994 \\
\hline $\operatorname{Gal}(\beta 1-4) \operatorname{GlcNAc}(\beta 1-6)-\operatorname{Gal}(\beta 1-4) \operatorname{Glc}-\operatorname{Gal}(\beta$ & ) lacto- $N$-novopentaose I & $\mathrm{c}$ & Urashima et al., 1991b \\
\hline $\mathrm{Gal}(\beta 1-4) \mathrm{Glc}-3^{\prime}-\mathrm{PO}_{4}$ & lactose-3'-O-phosphate & $\mathrm{b}$ & Cumar et al., 1965 \\
\hline $\operatorname{Fuc}(\alpha 1-2) \mathrm{Gal}(\beta 1-4) \mathrm{Glc}$ & 2-fucosyllactose & $\mathrm{c}$ & Urashima et al., 1994 \\
\hline \multicolumn{4}{|l|}{ Acidic oligosaccharides } \\
\hline $\operatorname{Neu} 5 \mathrm{Ac}(\alpha 2-3) \mathrm{Gal}$ & 3- $N$-acetylneuraminylgalactose & $\mathrm{b}$ & Kuhn and Gauhe, 1965 \\
\hline $\operatorname{Neu} 5 \mathrm{Ac}(\alpha 2-3) \mathrm{Gal}(\beta 1-4) \mathrm{Glc}$ & 3'- $N$-acetylneuraminyllactose & $\mathrm{b}, \mathrm{c}$ & Schneir et al., 1966; Urashima et al., 1997 \\
\hline $\operatorname{Neu} 5 \mathrm{Ac}(\alpha 2-6) \mathrm{Gal}(\beta 1-4) \mathrm{Glc}$ & 6'- $N$-acetylneuraminyllactose & $\mathrm{b}, \mathrm{c}$ & $\begin{array}{l}\text { Kuhn and Gauhe, 1965; Urashima et al., } \\
1997\end{array}$ \\
\hline $\operatorname{Neu} 5 \mathrm{Gc}(\alpha 2-3) \mathrm{Gal}(\beta 1-4) \mathrm{Glc}$ & 3'- $N$-glycolylneuraminyllactose & $\mathrm{b}$ & Kuhn and Gauhe, 1965 \\
\hline $\operatorname{Neu} 5 \mathrm{Gc}(\alpha 2-6) \mathrm{Gal}(\beta 1-4) \mathrm{Glc}$ & 6'- $N$-glycolylneuraminyllactose & b, c & Veh et al., 1981; Urashima et al., 1997 \\
\hline Neu5Ac( $\alpha 2-6)$ Gal $(\beta 1-4)-G l c N A c$ & 6'- $N$-acetylneuraminyllactosamine & $\mathrm{b}, \mathrm{c}$ & $\begin{array}{l}\text { Kuhn and Gauhe, } 1965 \text {; } \\
\text { Urashima et al., } 1997\end{array}$ \\
\hline Neu5Gc( $\alpha 2-6) \operatorname{Gal}(\beta 1-4)-G l c N A c$ & 6'- $N$-glycolylneuraminyllactosamine & $\mathrm{b}$ & Veh et al., 1981 \\
\hline $\operatorname{Neu} 5 \mathrm{Ac}(\alpha 2-8) \operatorname{Neu} 5 \mathrm{Ac}(\alpha 2-3)-\mathrm{Gal}(\beta 1-4) \mathrm{Glc}$ & di- $N$-acetylneuraminyllactose & $\mathrm{b}$ & Kuhn and Gauhe, 1965 \\
\hline $\operatorname{Neu} 5 \mathrm{Ac}(\alpha 2-3) \mathrm{Gal}-3 \mathrm{Gal1}-4 \mathrm{Glc}$ & 3"- $N$-acetylneuraminyl-3'-galactosyllactose & $\mathrm{b}$ & Parkkinen and Finne, 1987 \\
\hline Neu5Ac( $\alpha 2-6) \mathrm{Gal}(\beta 1-4)-\mathrm{GlcNAc}-1-\mathrm{PO}_{4}$ & 6'- $\mathrm{N}$-acetylneuraminyllactose-1-O-phosphate & $\mathrm{b}$ & Parkkinen and Finne, 1987 \\
\hline Neu5Ac( $\alpha 2-6) \mathrm{Gal}(\beta 1-4)-\mathrm{GlcNAc}-6-\mathrm{PO}_{4}$ & 6'- $N$-acetylneuraminyllactose-6- $O$-phosphate & $\mathrm{b}$ & Parkkinen and Finne, 1987 \\
\hline Neu5Ac( $\alpha 2-3)-\operatorname{Gal}(\beta 1-4)-\mathrm{Gal}(\beta 1-6) \mathrm{Glc}$ & $3^{\prime}-N$-acetylneuraminyl- $\beta 6$ '-galactosyllactose & $\mathrm{c}$ & Viverge et al., 1997 \\
\hline Neu5Ac( $\alpha 2-6)$-Gal $(\beta 1-3)-G a l(\beta 1-4)$ Glc & 6'- $N$-acetylneuraminyl- $\beta 3$ '-galactosyllactose & $\mathrm{c}$ & Viverge et al., 1997 \\
\hline
\end{tabular}

*b is regarded as bovine milk or colostrums.

$*_{c}$ is regarded as caprine milk or colostrums.

(Bode et al., 2004a), sialyl oligosaccharides can reduce the adhesion of leukocytes to endothelial cells, an indication for an immune-modulating effect of oligosaccharides in milk. It has been found among breastfed newborn infants that there is a lower rate of suffering from diarrhea, respiratory diseases and, in general, infectious diseases compared with formula-fed infants (Martinez-Ferez et al, 2006; Newburg, 1999).

There are many other bioactive roles of the oligosaccharides in milk have been identified; the beneficial functions of the oligosaccharides in humans were summarized as follows: (1) they supply small amounts of energy, approximately 0-3 kcal/g of sugar substitute, (2) they lower the absorption of dissolved glucose by forming a viscous gel in the gut, (3) they are non-cariogenic, (4) they inhibit diarrhea and symptoms of diarrhea, and (5) they cause protective effect against infection in the gastrointestinal, respiratory, and urogenital tracts (Manning and Gibson,
2004; Monchois et al., 1999; Ngo et al., 2008).

The structural complexity of HMO limits its applicability in population groups other than breast-fed children (Zivkovic and Barile, 2011). As some bovine milk oligosaccharides are structurally and functionally close to those found in human milk, it is presumable that bovine milk oligosaccharides could be the first choice to mimic the functions of human milk oligosaccharides (Gopal and Gill, 2000; Zivkovic and Barile, 2011). These functions could include prebiotic activity, inhibition of pathogen binding to epithelial cells, effects on immune response, reduction of inflammatory diseases, structural and functional roles in brain formation, and facilitation of mineral absorption.

\section{Prebiotic effects}

Milk oligosaccharides have been considered as beneficial for human health when it was known that this frac- 
tion of carbohydrate has prebiotic effects in infants (Kunz et al., 2000). Prebiotics are specified as non-digestible food elements which can affect the host by selectively stimulating the growth and/or activity of certain types of bacteria in the gut which can improve the host health (Gibson and Roberfroid, 1995). Observations on the metabolic fate of the milk oligosaccharides have indicated that these substances pass through the intestine to the colon without degradation where they induce the development of the health promoting bifidobacteria thus representing the paradigm of prebiotics (Coppa et al., 2001).

The prebiotic effect of milk although arises due to the activity of various components, oligosaccharides represent the major substances (Table 2). It is well evident that milk oligosaccharides modify the colonic flora of infants by increasing the number of useful bacteria accompanied with a significant reduction of pathogenic bacteria (Rivero-Urgell and Santamaria-Orleans, 2001).

The intestinal microbial population dominated by bifidobacteria and lactobacilli has many useful functions and include pathogen binding, modulation of mucosal physiology and barrier function, modulation of systemic immune response, prevention of traveler's diarrhea in children, improvement of constipation, and antibacterial and anticarcinogenic activities (Mills et al., 2011; Qiang et al., 2009). It is suggested that the first bacteria which dominate the infant's gastrointestinal tract are very important in determining the ultimate gut microbial composition because these colonizing bacteria later modify the immune response in various ways (Gronlund et al., 1999). Milk oligosaccharides are believed to stimulate the growth of bifidobacteria in the lower intestine and result in the reduction of $\mathrm{pH}$ due to the short-chain fatty acids (SCFA) produced from the fermentation of oligosaccharides by bifidobacteria. Low $\mathrm{pH}$ value in the colon and in the feces suppress the colonization of pathogenic bacteria (Mussatto and Manchilha, 2007; Urashima and Taufik, 2010).

It is generally believed that lactobacilli can protect the vaginal mucosa from pathogenic micoroorganisms by making up a biofilm on the mucosal surface; when the num- ber of lactobacilli are reduced, other pathogenic microorganisms can grow excessively. Milk oligosaccharides also can protect the urogenital infections by promoting the growth of lactobacilli (Rousseu et al., 2005; Qiang et al., 2009). Interestingly, some bovine milk oligosaccharides have the same structural and functional features as human milk oligosaccharides (Gopal and Gill, 2000; Urashima et al., 2001). Since the human intestine lacks the enzyme capable of hydrolyzing the $\alpha$ - and $\beta$-glycosidic linkages exist in the BMO, these oligosacchairdes can reach the colon without degradation, making them available to be utilized as prebiotics (Barile et al., 2009; Boehm and Stahl, 2003). Both bovine milk and colostrum are considered as a natural source of bioactive oligosaccharides and can be used in the medicinal foods (Urashima and Taufik, 2010).

\section{Anti-adhesion}

Milk oligosaccharides have anti-adhesion properties for both Gram-negative and Gram-positive bacteria (Hakkarainen et al., 2005; Zivkovic and Barile, 2011). The reason is attributed to the structural similarity between the non-reducing ends of milk oligosaccharides and the non-reducing ends of sugar chains of glycoconjugates lying across the surface of the epithelial cells (Urashima and Taufik, 2010). Milk oligosaccharides are actually synthesized by glycosyltransferases, which shape the sugar chains of the epithelial surface of the mammary gland (Schwertmann et al., 1996). It is believed that many viruses and bacteria start infection by binding to particular sugar chains of glycoconjugates on the surface cells lying on the mucous epithelium of digestive and respiratory tracts. As a consequence, milk oligosaccharides can act as a decoy of the target sugar chains of the pathogenic microorganisms on the epithelial surface (Kobata, 2010). In this way, oligosaccharides in milk may act in infants as additional protection whose stomach is not yet as acidic as in adults and moreover, whose immune system is not completely developed against enteric pathogens by inhibiting the mucosal adhesion of pathogenic agents to the intestinal surface

Table 2. Performance of milk components proposed as prebiotics (Coppa et al., 2006)

\begin{tabular}{|c|c|c|c|c|}
\hline Component & In vitro effect & Resistance to digestion & Clinical trials & Prebioitic effects \\
\hline Phosphates & $?$ & $?$ & - & No \\
\hline Proteins & $+/-$ & + & - & Minor (?) \\
\hline Lactoferrin & $?$ & ++ & $+/-$ & Possible \\
\hline Nucleotides & + & $?$ & $+/-$ & Uncertain \\
\hline Lactose & + & $+/-$ & - & Minor (?) \\
\hline Oligosaccharides & +++ & ++ & +++ & Documented \\
\hline
\end{tabular}


(Rivero-Urgell and Santamaria Orleans, 2001).

A study by Ruiz-Palacios et al. (2003) established that fucosylated milk oligosaccharides bind with the Campylobacter jejuni, which causes diarrhea and paralysis of motor nerves in infants. Helicobacter pylori, an ulcer causing microorganisms which inhabits in the gastric mucosa, is a big threat to human health these days. Nearly $50 \%$ of the total world populations become infected with this microorganism. On the face of it, sialylated milk oligosaccharides have been reported to inhibit the attachment of $H$. pylori to the epithelial surface of the stomach (Bode, 2006; Johansson et al., 2005) (Table 3). Kunz and Rudloff, (2006) lately described that milk oligosaccharides could play roles as ligands against some pathogens (Table 3).

It has been reported that bovine milk oligosaccharides can potentially be used as anti-infection agents. Hakkarainen et al. (2005) suggested that bovine neutral and acidic oligosaccharides at concentrations of $1-2 \mathrm{~g} / \mathrm{L}$ clearly inhibit the attachment of Neisseria meningitidis, a human-specific pathogen causing meningitis and septicemia. The oligosaccharide fraction in the supernatant form found in the milk of Swiss Brown cows was shown to inhibit the hemagglutination caused by some enterotoxigenic $E$. coli strains (Martin et al., 2002). These results suggest that milk oligosaccharides can act as a potential pathogen binding agent due to its structural resemblance with the glycoconjugates resting across the surface of the epithelial cells and thereby resist many infectious diseases.

\section{Immuno-modulation}

Another potential of oligosaccharides in milk have been shown to modulate the responses of the immune system (Schumacher et al., 2006). A minute amount of oligosaccharides is absorbed when pass through the gastrointestinal tract and is shown to have a spectrum of immunomodulatory functions by making direct interactions with the epithelia and the immune system. In human body the assimilated oligosaccharides can inhibit immune cell attachment in endothelial cells, induce the cytokine production in blood borne immune cells and help reduce the skin allergy. In addition, oligosaccharides can be utilized by dendritic cells and these cells are shown to have some beneficial functions on immunity development (Bode et al., 2004; Gruber et al., 2010; Niess et al., 2005; Rescigno et al., 2009; Zivkovic and Barile, 2011).

HMO has been found to be very efficient to give rise to a wide range of immuno-modulation effects with its capability to interact directly with the intestinal epithelial cells and enteroendocrine cells (Zivkovic and Barile, 2011). However, it is observed very recently that BMO is a potential source to mimic the benefits of HMO to produce immuno-modulatory effects. Lacto-N-fucopentaose III and lacto-N-neotetraose which are abundant in human milk can stimulate the production of IL-10, an anti-inflammatory cytokine. Surprisingly, a similar structure lacto$\mathrm{N}$-neotetraose has been detected in significant amount in bovine milk (Tao et al., 2009). Therefore, the potential of BMO to serve as a new source of health-promoting functional ingredients is enticing as it can produce quite similar immuno-modulatory functions like HMO due to structural resemblance.

\section{Anti-inflammation}

Milk oligosaccharides have lately drawn the attention as an anti-inflammatory agent. It has been designated that milk oligosaccharides have the substances very similar to the selectin-binding ligands (Mills et al., 2011; Rudloff et al., 1996). Selectins are regarded as the surface adhesion particles which are released from the injured tissue during inflammation process as chemical signals. Selectins aggregate many cells including neutrophils and blood cells, and it has been observed that this accumulation of cells has turned out to be injurious which in many cases leads to tissue destruction (Carden and Granger, 2000; Jungi et al., 1986; McEver, 1997; Peters et al., 1999; Schon et al., 2002).

As it is described, the acidic fraction of milk oligosaccharides competes with p-selectin glycoprotein ligand 1 (PSGL-1) for binding with P-selectin and hence reduces the platelet-neutrophil complex (PNC) formation up to $20 \%$ during inflammation (Bode et al., 2004b). Among

Table 3. Milk oligosaccharides as soluble receptors for potential pathogens (Kunz and Rudloff, 2006)

\begin{tabular}{lll}
\hline \multicolumn{1}{c}{ Pathogen } & Target tissue & \multicolumn{1}{c}{ Milk oligosaccharides } \\
\hline Escherichia coli & Urinary tract & Man $(\alpha 1-3)[\operatorname{Man}(\alpha 1-6)] \mathrm{Man}-$ \\
Haemophilus influenza & Respiratory tract & $\operatorname{NeuAc}(\alpha 2-3)_{0.1} \mathrm{Gal}(\beta 1-4) \mathrm{GlcNAc}(\beta 1-4) \mathrm{GlcNAc}-$ \\
Helicobacter pylori & Stomach & $\operatorname{NeuAc}(\alpha 2-3) \mathrm{Gal}(\beta 1-4) \mathrm{Glc}(\mathrm{NAc})$ \\
& & $\mathrm{Fuc}(\alpha 1-2) \mathrm{Gal}(\beta 1-3)[\mathrm{Fuc}(\alpha 1-4)] \mathrm{Gal}$ \\
Streptococcus pneumoniae & Respiratory tract & NeuAc $(\alpha 2-3)_{0.1} \mathrm{Gal}(\beta 1-4) \mathrm{GlcNAc}(\beta 1-4) \mathrm{GlcNAc}$ \\
\hline
\end{tabular}


many of the p-selecting binding, sialylated milk oligosaccharides 3'-sialyl-lactose and 3'-sialyl-3-fucosyl lactose are the most prominent (Bode et al., 2004a). It is however identified that acidic component of milk oligosaccharides alone is more effective than total milk oligosaccharides (Schumacher et al., 2006). Furthermore, it is noteworthy that SCFA result from milk oligosaccharides have the capacity to bind with GPR43, a substance secreted by immune cells as an inflammatory immune response. This mechanism was realized when it was first noticed that the treatment of some germ free mice suffering from induced colitis with acetate could remarkably reduce the disease indices (Maslowski et al., 2009). The lower incidence of infectious and inflammatory diseases in the breast-fed babies indicates that HMO plays a significant role to resist inflammation. Likewise, BMO has the potential to modulate the inflammatory immune response as it is abundant in acidic oligosaccharides.

\section{Brain development}

The sialylated oligosaccharides found both in bovine and human milks have been proven to play essential roles in the development of brain and central nervous system (Wang and Brand-Miller, 2003). It was demonstrated that a little amount of sialylated oligosaccharides are taken up through the digestive tracts in the suckling babies and essentially utilized for the biosynthesis of gangliosides and glycoproteins in its brain (Bogoch et al., 1977; Schmidt, 1989). Gangliosides and glycoproteins are very crucial in the formation of memory and learning. The sialic acids present in gangliosides and glycoproteins play both structural and functional roles in the brain cortex which include cell recognition, cell-to-cell contact, receptor binding and modulation, immunological properties and biosignal transduction neurotransmitters. Moreover, in the central nervous system sialic acid acts as a receptor for neurotransmitters (Mills et al., 2011; Von Itzstein and Thomson, 1997; Wang and Brand-Miller, 2003).

The importance of milk oligosaccharides in brain formation and functioning have been supported by previous studies which claimed that intelligence skills were surprisingly higher in the suckling babies than the formulafed babies (Fergusson et al., 1982; Lucas et al., 1992; Smith et al., 2003). In animal studies it was found that feeds containing protein-bound sialic acid can enhance the learning and memory during early development (Mills et al., 2011; Wang et al., 2007b). Furthermore, the role of sialic acid in binding of $\mathrm{Ca}$ to ganglioside which has a great effect on the function of nervous tissue cannot be overemphasized (Schaur and Kamerling, 1997). Interestingly, one assessment of bovine colostrum and milk between prepartum and early lactation confirmed the abundance of sialyl oligosaccharides in bovine milk and suggested that bovine milk can be a potential source of sialyloligosaccharides as additives in the food or pharmaceutical industries (Nakamura et al., 2003).

\section{Mineral absorption}

Milk oligosaccharides evolve as an important phenomena when it comes to intestinal and colonic mineral absorption. It was pointed that milk oligosaccharides can induce the absorption and retention of calcium, magnesium, iron, and zinc (Boehm and Stahl, 2003). A study on rat revealed that dietary intake of milk oligosaccharides could successfully stimulate the $\mathrm{Ca}$ absorption (Chonan and Watanuki, 1996). Positive effects of milk oligosaccharides also were found for magnesium, iron and zinc absorption (Heuvel et al., 1998; Scholz-Ahrens et al, 2001). Surprisingly, in human study it was observed that an infant formula supplemented with milk oligosaccharides resulted in the presence of higher amount of calcium in the renal excretion than that found in the case of nonsupplemented formula, which clearly indicates that the supplemented formula increases $\mathrm{Ca}$ absorption (Boehm and Stahl, 2003). A substantial increase in calcium absorption was also noticed in a group of postmenopausal women supplied with oligosaccharides in milk and other diets (Heuvel et al., 2000).

There are several possible mechanisms through which milk oligosaccharides can facilitate the mineral absorption. Most importantly, bifidobacterial fermentation of milk oligosaccharides increases production of SCFA resulting in a decrease in $\mathrm{pH}$ which eventually facilitate the solubility of minerals to be absorbed through the gut. It is also assumed that milk oligosaccharides play roles to increase mineral transport in the small intestine as well as from the small intestine to the colon (Scholz-Ahrens et al., 2001). Though there are a number of factors can be considered to take part in mineral absorption, milk oligosaccharides accompanied by the oligosaccharides from some other sources are in the forefront in facilitating mineral absorption in the intestine and colon.

\section{Conclusion}

Bioactive functions of milk oligosaccharides are long familiar now. Scientific studies have unveiled that milk oligosaccharides harbor the colonic and intestinal microf- 
lora while these components make the gut environment adverse to the survival of the pathogenic microbes. The functions of milk oligosaccharides in the modulation of immune response, intestinal mineral absorption, and brain development are well documented. Many other functions of milk oligosaccharides are being pointed by recent studies but still further comprehensive experiments are needed. Although human milk has the most diverse and complex array of oligosaccharides, synthetic production of HMO is impracticable due to its structural complexity. Therefore, alternative sources are on the quest to mimic the functions of HMO. On that pursuit, BMO have been found to have similar structural features like HMO and is presumed to be utilized as a substitute of HMO in different functional foods on industrial scale.

\section{Acknowledgement}

This study was supported by the Brain Korea 21 Project in Seoul, Korea.

\section{References}

1. Barile, D., Marotta, M., Chu, C., Mehra, R., Grimm, R., Lebrilla, C. B., and German, J. B. (2010) Neutral and acidic oligosacchrarides in Hostein-Friesian colostrums during the first 3 days of lactation measured by high performance liquid chromatography on a microfluidic chip and time-of-flight mass spectrometry. J. Dairy Sci. 93, 3940-3949.

2. Barile, D., Tao, N., Lebrilla, C. B., Coisson. J-D., Arlorio, M., and German, J. B. (2009) Permeate from cheese whey ultrafiltration is a source of milk oligosaccharides. Int. Dairy $J$. 19, 524-530.

3. Bode, L. (2006) Recent advances on structure, metabolism and function of human milk oligosaccharides. J. Nutr. 136, 2127-2130.

4. Bode, L., Kunz, C., Muhly-Reinholz, M., Mayer, K., Seeger, W., and Rudloff, S. (2004a) Inhibition of monocyte, lymphocyte and neutrophil adhesion to endothelial cells by human milk oligosaccharides. J. Throm. Haemost. 92, 1402-1410.

5. Bode, L., Rudloff, S., Kunz, C., Strobel, S., and Klein, N. (2004b) Human milk oligosaccharides reduce platelet-neutrophil complex formation leading to a decrease in neutrophil beta 2 integrin expression. J. Leukocyte Biol. 76, 820-826.

6. Boehm, G. and Moro, G. (2008) Structural and functional aspects of prebiotics used in infant nutrition. J. Nutr. 138, 1818S-1828S

7. Boehm, G. and Stahl, B. (2007) Oligosaccharides from milk. J. Nutr. 137, 847S-849S.

8. Boehm, G. and Stahl, B. (2003) Oligosachardes. In: Functional dairy products. Mattila-Sandholm, T. (ed) Woodhead publishers, Cambridge, UK, pp. 203-243.

9. Bogoch, S. (1977) Recognins and their chemoreciprocals. In:
Behavioural neurochemistry. DeFeudis, F. V., and Delgado, J. M. (eds) Spectrum Publishers, New York, NY, USA, p. 270.

10. Carden, D. L. and Granger, D. N. (2000) Pathophysiology of ischaemia-reperfusion injury. J. Pathol. 190, 255-266.

11. Chonan, O. and Watanuki, M. (1996) The effect of 6'-galactooligosaccharides on bone mineralization of rats adapted to different levels of dietary calcium. Int. J. Vitam. Nutr. 66, 244-249.

12. Coppa, G. V., Zampini, L., Galeazzi, T., and Gabrielli, O. (2006) Prebiotics in human milk: a review. Digest. Liver Dis. 38, S291-S294.

13. Coppa, G. V., Pierani, P. Zampini, L., Bruni, S., Carloni, I., and Gabrielli O. (2001) Characterization of oligosaccharides in milk and feces of breast-fed infants by high performance anion-exchange chromatography. Adv. Med. Biol. 501, 307314.

14. Cumar, F. A., Ferchmin, P. A., and Caputto, R. (1965) Isolation and identification of a lactose phosphatase ester from cow colostrums. Biochem. Biophys. Res. Comm. 20, 60-62.

15. Fergusson, D. M., Beautrais, A. L., and Silva, P. (1982) Breastfeeding and cognitive development in the first seven years of life. Soc. Sci. Med. 16, 1705-1708.

16. Gibson, G. and Roberfroid, M. (1995) Dietary modulation of human colonic microbiota-introducing the concept of probiotics. J. Nutr. 125, 1401-1412.

17. Gopal, P. K. and Gill, H. S. (2000) Oligosaccharides and glycoconjugates in bovine milk and colostrums. Brit. J. Nutr. 84, 69-74.

18. Gronlund, M. M., Lehtonen, O. P., Eerola, E., and Kero, P. (1999) Fecal microflora in healthy infants born by different methods of delivery: permanent changes in intestinal flora after caesarean delivery. J. Pediat. Gastroenterol. Nutr. 28, 19-25.

19. Gruber, C., van Stuijvenberg M., Mosca, F., Moro, G., Chirico, G., Braegger, C. P., Riedler, J., Boehm, G., and Wahn, U. (2010) Reduced occurrence of early atopic dermatitis because of immunoactive prebiotics among low-atopy-risk infants. $J$. Alergy Clin. Immunol. 126, 791-797.

20. Hakkarainen, J., Toaiven, M., Leinonen, A., Frangsmyr, L., Stromberg, N., Lapinjoki, S., Nasssif, X., and Tikkanen-Kaukanen, C. (2005) Human and bovine milk oligosaccharides inhibit Neisseria meningitidis pili attachment in vitro. $J$. Nutr. 135, 2445-2448.

21. Heuvel van den E. G., Schoteraman, M. H., and Muijs, T. (2000) Transgalacto-oligosaccharides stimulate calcium absorption in postmenopausal women. J. Nutr. 130, 2938-2942.

22. Heuvel van den E. G., Schaafsma G., Muys T., and Dokkum van, W. (1998) Non digestible oligosaccharides do not interfere with calcium and nonhem-iron absorption in young, healthy men. Am. J. Clin. Nutr. 67, 445-451.

23. IUPAC/IUBMB (1997) Joint Commission on Biochemical Nomenclature (JCBN) Nomenclature of Carbohydrates, Recommendations 1996. Carbohydr. Res. 297, 1-90.

24. Johansson, P., Nilsson, J., Angstrom, J., and Meller-Podraza, H. (2005) Interaction of Helicobacter pylori with sialylated 
carbohydrates: the dependence on different parts of the binding trisaccharides Neu5Aco3Galß4GlcNAc. Glycobiol. 15, 625-636.

25. Jungi, T. W., Spycher, M. O., Nydegger, U. E., and Barandun, S. (1986) Platelet-leukocyte interaction: selective binding of thrombin-stimulated platelets to human monocytes, polymorphonuclear leukocyte, and related cell lines. Blood 67, 629-636.

26. Kimura, K., Watanabe, Y., Matsumoto, K., and Miyagi, A. (1997) Yakult Reports 17, 1-7.

27. Kuhn, R., and Gauhe, A. (1965) Bestimmung der bindungsstellen von sialinsaure-resten in oligosacchariden mit hilfe von perjodat. Chem. Ber. 98, 395-413.

28. Kobata, A. (2010) Structures and application of oligosaccharides in human milk. Proc. Jpn. Acad., Ser. B. 86, 731-747.

29. Kobata, A., Grollman, E. F., Torain, B. F., and Ginsburg, V. (1970) Blood and tissue antigens. Academic press, New York, USA, pp. 497.

30. Kunz, C. and Rudloff, S. (2006) Health promoting aspects of milk oligosaccharides. Int. Dairy J. 16, 1341-1346.

31. Kunz, C., Rudloff, S., Baier, W., Klein, N., and Strobel, S. (2000) Oligosaccharides in human milk. Structural, functional, and metabolic aspects. Annu. Rev. Nutr. 20, 699-722.

32. Lucas, A., Morley, R., Cole, T. J., Lister, G., and LeesonPayne, C. (1992) Breast milk and subsequent intelligence quotient in children born preterm. Lancet 339, 261-264.

33. Manning, T. S., and Gibson, G. R. (2004) Prebiotics. Best Prac. Res. Clin. Gastro. 18, 287-298.

34. Martinez-Ferez, A., Rudloff, S., Guadix, A., Henkel, C. A., Phlents, G., Boza, J. J., Guadix, E. M., and Kunz, C. (2006) Goats' milk as a natural source of lactose-derived oligosaccharides: Isolation by membrane technology. Int. Dairy J. 16, 173-174.

35. Martin, M. J., Martin-Sosa, S., and Hueso, P. (2002) Binding of milk oligosaccharides by several enterotoxigenic Eschecrichia coli strains isolated from calves. Glycoconj. J. 19, 511.

36. Martin, M. J., Marin-Sosa., S. Garcia-Pardo, L. A., and Hueso, P. (2001) Distribution of bovine sialoglycoconjugates during lactation. J. Dairy Sci. 84, 995-1000.

37. Maslowski, K. M., Vieira, A. T., Ng, A., Kranich, J., Sierro, F., Yu, D., Schilter, H. C., Rolph, M. S., Mackay, F., Artis, D., Xavier, R. J., Teixeira, M. M., and Mackay, C. R. (2009) Regulation of inflammatory responses by gut microbiota and chemoattractant receptor GPR43. Nature 461, 1282-1286.

38. McEver, R. P. (1997). Selectin-carbohydrate interactions during inflammation and metastasis. Glycoconj. J. 14, 585591.

39. Mehra, R., and Kelly, P. (2006) Milk oligosaccharides: structural and technological aspects. Int. Dairy J. 16, 1334-1340.

40. Mills, S., Ross, R. P., Hill, C., Fitzgerald, G. F., and Stanton, C. (2011) Milk intelligence: Mining milk of bioactive substances associated with human health. Int. Dairy J. 21, 382386.

41. Monchois, V., Willemot, R. M., and Monsan, P. (1999) Glucansucrases: Mechanism of action and structure-function relationships. FEMS Microbiol. Rev. 23, 131-151.

42. Mussatto, S. I., and Manchilha, I. M. (2007) Non-digestible oligosaccharides: A review. Carbohydr. Polymers 68, 587597.

43. Nakamura, T., Kawase, H., Kimura, K., Watanabe, Y., Ohtani, M., Arai, I., and Urashima, T. (2003) Concentrations of sialyloligosaccharides in bovine colostrums and milk during the prepartum and early lactation. J. Dairy Sci. 86, 1315-1320.

44. Newburg, D. S. (1999) Human milk glycocnjugates that inhibit pathogens. Curr. Med. Chem. 6, 117-127.

45. Ngo, D.-N., Kim, M.-M., and Km, S.-K. (2008) Chitin oligosaccharides inhibit oxidative stress in live cells. Carbohyd. Polym. 74, 228-234.

46. Niess, J. H., Brand, S., Gu, X., Landsman, L., Jung, S., McCormick, B. A., Vyas, J. M., Boes, M., Ploegh, H. L., Fox, J. G., Littman, D. R., and Reinecker, H. C. (2005) $\mathrm{CX}_{3}$ CR1mediated dendritic cell access to the intestinal lumen and bacterial clearance. Science 307, 254-258.

47. Ninonuevo, M. R., Park, Y., Yin, H., Zhang, J., Ward, R. E., Clowers, B. H., German, J. B., Freeman S. L., Killeen, K., Grimm, R., and Lebrilla, C. B. (2006) A strategy for annotating the human milk glycome. J. Agric. Food Chem. 54, 74717480 .

48. Parkkinen, J., and Finne, J. (1987) Isolation of sialyl oligosaccharides and sialyl oligosaccharide phosphates from bovine colostrums and human urine. In: Methods in Enzymology Ginsberg, V. (ed) Academic Press, New York. Vol. 138, pp. 289-300.

49. Peters, M. J., Dixon, G., Kotowicz, K. T., Hatch, D. J., Heyderman, R. S., and Klein, N. J. (1999) Circulating plateletneutrophil complexes represent a subpopulation of activated neutrophils primed for adhesion, phagocytosis and intracellular killing. Brit. J. Haematol. 106, 391-399.

50. Qiang, X., YongLie, C., and QiaBing, W. (2009) Health benefit application of functional oligosaccharides. Carbohyd. Polym. 77, 435-441.

51. Rescigno, M. and Di Sabatino, A. (2009) Dendritic cells in intestinal homeostasis and disease. J. Clin. Invest. 119, 24412450.

52. Rivero-Urgell M., and Santamaria-Orleans, A. (2001) Oligosaccharides: application in infant food. Early Human Develop. 65, S43-S45.

53. Rousseu, V., Lepargneur, J. P., Roques, C., Remaud-Simeon, M., and Paul, F. (2005) Prebiotic effects of oligosaccharides on selected vaginal lactobacilli and pathogenic microorganisms. Anaerobe 11, 145-153.

54. Rudloff, S., Phlentz, G., Diekmann, L., Egge, H., and Kunz, C. (1996) Urinary excretion of lactose and oligosaccharides $\mathrm{n}$ preterm infants fed human milk or infant formula. Acta Paedeatr. 85, 598-603.

55. Ruiz-Palacios, G. M., Cervantes, L. E., Ramos, P., ChavezMunguia, B., and Newburg, D. S. (2003) Campylobacter jejuni binds intestinal $\mathrm{H}(\mathrm{O})$ antigen (Fuc $\alpha 1,2$ Gal $\beta 1,4$ GlcNAc), and fucosyloligosaccharides of human milk inhibit its binding and infection. J. Biol. Chem. 278, 14112-14120.

56. Sabharwal, H., Sjoblad, S., and Lundblad, A. (1991) Affinity 
chromatographic identification and quantification of blood group A-active oligosaccharides in human milk and feces of breast-fed infants. J. Pediatr. Gastroenterol. Nutr. 12, 474479.

57. Saito, T., Itoh, T., and Adachis, S. (1987) Chemical structure of three neutral trisaccharides isolated in free form from bovine colostrums. Carbohydr Res. 165, 43-51.

58. Saito, T., Itoh, T., and Adachi, S. (1984) Presence of two neutral disaccharides containing $\mathrm{N}$-acetylhexosamine in bovine colostrums as free forms. Biochem. Biophys. Acta 801, 147150.

59. Schaur, R., and Kamerling, J. P. (1997) Chemistry, biochemistry and biology of sialic acids. In: Glycoproteins II, Schachter, H., Montreuil, and Vilegenthart, J. F. G. (eds) Elsvier, Amsterdam, The Netherlands, pp. 243-372.

60. Scheneir, M. L. and Rafelson, M. E. (1996) Isolation of two structural isomers of $\mathrm{N}$-acetylneuraminyllactose from bovine colostrum. Biochem. Biophys. Acta 130, 1-11.

61. Schimdt, R. (1989) Glycoproteins involved in long-lasting plasticity in the teleost brain. Forts. Zool. 37, 327-339.

62. Scholz-Ahrens, K., Schsafsma, G., Van Del Heuvel E. G. M. J., and Schrezenmeir J (2001) Effect of Prebiotics in mineral metabolism. Am. J. Clin. Nutr. 73, 459S-464S.

63. Schon, M. P., Krahn, T., Schon, M., Rodriquez, M. -L., Antonicek, H., Schultz, J. E., Ludwiq, R. J., Zollner, T. M., Bischoff, E., Bremm, K. D., Schramm, M., Henninger, K., Kaufmann, R., Gollnick, H. P. Parker, C. M., and Boenchke, W. H. (2002) Efomycine $\mathrm{M}$, a new specific inhibitor of selectin, impairs leukocyte adhesion and alleviates cutaneous inflammation. Nature Med. 8, 366-372.

64. Schumacher, G., Bendas, G., Stahl, B., and Beermann, C. (2006) Human milk oligosaccharides affect P-selectin binding capacities: in vitro investigation. Nutr. 22, 620-627.

65. Schwertmann, A., Rudloff, S., and Kunz, C. (1996) Potential ligands for cell adhesion molecules in human milk. Ann. Nutr. Metab. 40, 252-262.

66. Smith, M. M., Durkin, M., Hinton, V. J., Bellinger, D., and Kuhn, L. (2003) Influence of breastfeeding on cognitive outcomes at age 6-8 years: follow-up of very low birth weight infants. Am. J. Epidem. 158, 1075-1082.

67. Tao, N., DePeters, E. J., Freeman, S. German, J. B., Grimm, R., and Lebrilla, C. B. (2009) Variations in bovine milk oligosaccharides during early and middle lactation stages analyzed by high-performance liquid chromatography-chip/mass spectrometry. J. Dairy Sci. 92, 2991-3001.
68. Tao, N., DePeters, E. J., Freeman, S., German, J. B., Grimm, R., and Lebrilla, C. B. (2008) Bovine milk glycome. J. Dairy Sci. 91, 3768-3778.

69. Urashima, T. and Taufik, T. (2010) Oligosaccharides in milk: Their benefits and future utilization. J. Anim. Sci. Technol. 33, 189-197.

70. Urashima, T., Saito, T., Nakamura, T., and Messer, M. (2001) Oligosaccharides of milk and colostrums in non-human mammals. Glycoconj. J. 18, 357-371.

71. Urashima, T., Saito, T., and Nakamura, T. (1997b) Structural determination of mono-sialyltrisaccharides obtained from caprine colostrum. Comp. Biochem. Physiol. 116, 431-435.

72. Urashima, T., Bubb, W. A., Messer, M., Tsujii, Y., and Taneda, Y. (1994) Studies of the neutral trisaccharides of goat (Capra hircus) and of the one- and two-dimensional ${ }^{1} \mathrm{H}$ and ${ }^{13} \mathrm{C}$ NMR spectra of 6 - $\mathrm{N}$-acetylglucosaminyllactose. Carbhydr. Res. 269, 173-184.

73. Urashima, T., Saitu, T., and Kimura, T. (1991b) Structural determination of three neutral oligosaccharides in bovine (Holstein-Friesian) colostrum. Comp. Biochem. Biophys. Acta 1073, 225-229.

74. Veh, R. W., Michalski, J. C., Corfield, A. P., Sander-Wewer, M., Gies, D., and Schauer, R. (1981) New chromatographic system for the rapid analysis and preparation of colostrum sialyloligosaccharides. J. Chromatogr. 212, 313-322.

75. Viverge, D., Grimmonprez, L., and Solere, M. (1997) Chemical characterization of sialyl oligosaccharides isolated from goat (capra hircus) milk. Biochem. Biophys. Acta 1336, 157164.

76. Von Itzstein, M. and Thomson, R. J. (1997) Sialic acid and sialic acid-recognizing proteins: drug discovery targets and potential glycopharmaceuticals. Curr. Med. Chem. 4, 185210.

77. Wang, B., Yu, B., Karim, M., Hu, H., Sun, Y., McGreevy, P., et al. (2007b) Dietary sialic acid supplementation improves learning and memory in piglets. Am. J. Clin. Nutr. 85, 561569.

78. Wang, B. and Brand-Miller, J. (2003) The role and potential of sialic acid in human nutrition. Eur. J. Clin. Nutr. 57, 13511369.

79. Zivkovic, A. M. and Barile, D. (2011) Bovine milk as a source of functional oligosaccharides for improving human health. Adv. Nutr. 2, 284-288.

(Received 2011.7.6/Revised 2011.9.28/Accepted 2011.10.6) 